\title{
THE TEACHING OF SOCIOLOGY
}

\author{
JAMES QUAYLE DEALEY \\ Brown University
}

The methodology of sociology has so often been set forth in formal volumes and in elaborated articles, that nothing more on this subject for the present needs to be said. But, given these formal discussions, there still may be occasion for statements in respect to methods of application, so as to show how in actual teaching the content of sociology may be built up in quantity and quality. The writer in attempting such an exposition disclaims any desire to depict a model procedure, and, admitting that one's "personal equation" always includes a fraction of error, he craves pardon for his sins of omission and commission and for the intrusion of personal methods, pleading in extenuation orders from the honorable President of this association.

Under the name of social science sociology has been taught at Brown University for nearly twenty years. In 1906 the growing importance of the subject resulted in the establishment within the department of a chair of sociology and this has been ably filled since that date by Dr. Lester F. Ward. Professor Ward now has charge of the advanced classes in sociology, using his own methods and system, so that the following remarks apply only to courses formerly or at present given by other members of the department.

In social studies proper we have about three hundred students a year, receiving them into our classes from the beginning of the sophomore year. In these courses the practical problem of teaching a difficult subject to large classes with the utmost economy of expense and energy has compelled us to limit ourselves in the main to the presentation of the fundamental aspects of sociology, and hence we were under the necessity of deciding what these fundamentals are.

In the early years of the department it seemed rather necessary occasionally to dogmatize, arguing that there really was 
already existent a science of sociology. When one had a sort of suspicion that possibly there was no such science, there was a temptation to try all the harder to prove its existence; but as that secret suspicion faded away before the facts in the case, these were allowed to speak for themselves. Hence in recent years we have rather sought to present arguments showing that there is, or at any rate must be, such a science.

In asserting that there must be a science of sociology we have sought to show (I) the several senses in which the word science may be used; (2) the need of a general science to co-ordinate and to synthesize the teachings of those special sciences devoted to the study of social institutions and their activities; (3) the need of a science able to give a social interpretation to the teachings of biology and psychology; and (4) the necessity for a science that can absorb and assimilate into a logical unity all knowledge bearing with any directness on the past, present, and future of human society. Only by developing such a science, it is argued, can society hope to look with any confidence toward the future, and by a clear understanding of conditions and principles, thereby work consciously toward a higher standard of civilization.

In asserting, however, the necessity for the existence of sociology we have become careful not to dogmatize overmuch. If a student prefers to believe in the non-existence of the science, we are very willing to supply him with references in support of his view. If another calls attention to errors and defects in the sociological scheme, we would not hesitate to call his attention to others also that he had failed to see. If a third showed that former sociological teachings had become obsolete, we would further admit that much of what is now sociology may also become obsolete in a few years. In fact we long ago became convinced that pure and unadulterated truth unmixed with error is not the predominating characteristic of sociological teachings. Yet, after all these admissions have been made, we should still assert our right to continue the teaching of sociology, believing that, while theories may come and theories may go, yet the idea of a unifying science of human association will remain as a permanent achievement of the human mind. Even if at this 
moment we ourselves should admit that there is existent no science of sociology, and that the term merely represented an "attitude of mind," we would the next instant set about the making of the science, for the idea of it is fully born and a place must be made for it sooner or later among the sciences. Under such conditions the sociologist would simply have to maintain a faith in "the substance of things hoped for," or else dream prophetically of a future such as that Joseph dreamed about when his brothers' sheaves bowed themselves before him.

In the second place it has seemed to us important to distinguish carefully between the special social sciences devoted to some particular aspect or institution of society, and sociology proper as the science of laws and principles underlying human association. Here I must admit a dilemma arises. As a teacher of political science shall I assert with Brother Ford that there is no science of sociology, or as a sociologist shall I vindicate with Brother Small the right of sociology to exist? ${ }^{1}$ This is a question of no small importance and one cannot afford to dismiss it summarily. Yet the admission must be made that almost from the beginning at Brown political science and sociology have had their respective jurisdictions marked out, a modus vivendi agreed on, and peace maintained by having both subjects taught by the same teachers. Through these precautions we have never really had need to discuss the matter, but have naturally assumed that sociology is a science outranking the other in the hierarchy of the social sciences. Furthermore, the department of economics has always been in close affiliation with our department, so that in teaching these three great branches of human knowledge we have steadily worked together, harmonizing courses and agreeing on the several "spheres of influence" of these sciences.

In respect to other departments where friction might conceivably arise, time has brought about a full recognition of sociology's right to exist, and though our treaties of amity and peace have occasionally assumed the form of an armistice on the field of battle, yet there is in general an acknowledgement that several sciences may cover all or parts of the same field of phenomena

${ }^{1}$ See Controversy, American Journal of Sociology, Vol. XV, Nos. I and 2. 
but each from a different viewpoint. There is also a general recognition that the growing unity of knowledge can best be expedited by admitting one another's right to exist and by appointing when necessary boards of arbitration for the settlement of boundary disputes-under instructions to award disputed territory to the one most clearly in possession.

Again, in marking out the relationship existing between sociology and the special social sciences, we have made no attempt to assert authority over these, except in so far as specialized studies in social problems such as charity, crime, and the like have by common consent been given over to the department. These studies, however, have been carried on in the light of the dominating thought underlying sociology, viz., that the perplexing phenomena of human association are all parts of a common problem, and hence that a unifying idea should run through them all. This is done by emphasizing a common method, and the processes of co-ordination and synthesis. Emphasis is constantly placed on the methods of observation, comparison, and historical development, using as far as possible statistics as an essential aid in exact knowledge. Causes and conditions, as far as these can be ascertained, are sought out: the great social institutions are studied historically, analyses made of their component parts, these compared in their several stages of development, and resemblances and differences noted. Preferably a topical outline and references are used in the classroom, so as to allow the individuality of the student to express itself in results. Our compact little state (Rhode Island) with its dense urban population is used as a sort of laboratory where unconscious social experiments may constantly be observed and compared with similar phenomena in other social groups. As quite similar methods are usual in the other social sciences, there is a constant tendency to utilize the conclusions reached by these and to co-ordinate and synthesize them into a body of knowledge useful for sociological purposes. We discuss, for instance, such generalizations as: the influence of natural physical conditions and economic achievements in determining or tending to determine the trend of civilization; or the intimate connection between the material and the cultural aspects 
of civilization; or the struggle of class with class; or the social importance of a class freed from the necessity of economic toil; or the respective advantages and disadvantages of a static rigid civilization as against one flexible and dynamic by nature; or applications of biological and psychological knowledge to such practical problems as pauperism, crime, and sexual vice.

Such and similar generalizations can be used in a practical way as working hypotheses until confirmed or modified by further study. When seen, appreciated, and applied by the student they not infrequently arouse an interest that becomes permanent, with inevitable consequences in respect to his attitude toward the whole social question. Presumably for some time to come this synthesizing process applied to the conclusions of the special social sciences will furnish to sociology its most fruitful field of usefulness, by enabling it to exert a unifying influence on all social problems and by developing a constructive rather than a descriptive aspect to problems of social betterment. Furthermore it seems to the writer that sociology already has at its command a sufficient body of information to enable it to develop a tentative but constructive policy in respect to social problems. Haste should be made slowly and radicalism looked on askance, but the occasional blunders made in sociological suggestion will presumably in no case be worse than the continuous blunder of a policy of drift and inaction.

Our next step in the process of building up the content of sociology is to become familiar with social interpretations of the great teachings in well-established and historic departments of knowledge. Of these biology and psychology as basal sciences for sociology naturally furnish the chief material. Yet we are careful to show that sociology is no more psychology than psychology is biology, or biology, physics. These general sciences, as they develop new principles, or prove or disprove earlier hypotheses, furnish subject-matter for the consideration of the sociologist. The presumption is that such principles will have their analogies in social life also, and hence it is rather natural under the influence of the teachings from these other sciences to make use of a mechanical or a biological or a psychological interpretation of society or to 
assume too readily the truth of a materialistic interpretation of social development. Here we maintain the sociologist walks on treacherous ground, for experience shows that there is danger in pressing too far analogies derived from other sciences. Even the sociological use of a vocabulary made up from another science may be misleading, since it is so easy to carry over with a word itself its implications. Rather it may be wiser to seek first to comprehend the full significance of the particular principle or term in its relation to its own science, and then by observation and comparison to see whether a similar principle holds in social life, and in what respect it differs if at all from the kindred principle derived from the earlier science. For example the principle of natural selection and the term "heredity" seem simple enough on their face, yet, in view of the numerous variations in biological explanation of them there would inevitably arise as many confusing variations in interpretation of the term "social selection" or "social heredity," if students felt inclined to press analogies too far. Presumably also an endless confusion might arise if one were to carry over with the term "social mind" all the possibilities inherent in the varying interpretations of the psychological term "mind." While therefore such analogies have their use, and may by chance really throw much light on complex social phenomena, yet the danger of error is large and much of the force of the argument directed against the scientific nature of sociology really is aimed at those who have made hobbies of analogies to the neglect of the more scientific attainment preferred in sociological methodology. On the other hand the real sociological utility of applications of principles derived from the basal sciences may be noted, for example, in the biological contribution passing into the new science of eugenics, or as it might better be termed "eudemics," 2 supplemented as it must be by social studies of the domestic institutions; or again by noting how psychological principles may be reinterpreted from the sociological standpoint, and, by emphasis on newer aspects, give rise thereby to such attractive studies as folk psychology, social psychology, and social control, fields of study full of the promise of future usefulness.

" A term suggested by Librarian H. L. Koopman, Brown University. 
There is still another aspect of sociology-deemed worthy of emphasis in our teaching. The historical method should be applied to sociological theories themselves and the great social theories of past generations should be studied and compared with the teachings of the sociologists of the nineteenth century. By this method fundamental agreements and differences can be noted, the trend in the current of sociological theorizing can be indicated, and from the teaching of all of these thinkers can slowly be constructed a framework which later writers may fill out in detail. Furthermore such a historical study will enable the student to see why sociology in its upward march has been influenced first by mechanical theories of development, then by biological analogies resulting in the organic interpretation of society, then by the rise of the "social mind" under the influence of the newer psychology, and how, throughout the entire period, the conclusions of economics as the most fundamental of all the special social sciences have exercised a powerful influence on sociological theory.

Now when once the student grasps the thought that sociology is not to be identified with concrete studies of social problems, nor with economic, political, ethical, psychological, or biological studies as such, but rather with broad generalizations found in these as laws and principles of human association, and when furthermore he sees that others before him have labored to arrange in systematic and logical form these fundamentals, he is then prepared to see the real meaning of sociology as an abstract science. Indeed it is better that he should see this than that he become expert in what is often referred to as "social pathology" or "social philanthropy." If only he can be brought to see that there are fundamental teachings underlying human association, he will in later and more concrete studies tend to "put things in their places" and will not lose himself in detail, as might be possible if he were allowed to devote his energy exclusively to the innumerable perplexing problems of our highly complex civilization.

When once the student can be brought to see that in theory at least there may be a science of sociology, the remaining task should then be comparatively easy. He starts with an attitude of 
mind, a way of looking at and of interpreting social phenomena, and a reliance on the methods of science in order to secure verifiable knowledge. With Comte he will learn gradually to abjure metaphysical discussions. Admitting, as one must, that final explanations and questions in respect to the ultimate are worth asking and may at some distant time be answered, yet it seems more worth while to relegate this search to philosophy and to content one's self with an anthropocentric interpretation of things taking place on the earth or at most within the solar system. By ignoring the ultimate in this manner the sociologist admits an "ignoramus" in some matters and hence again may refuse to dogmatize, preferring to emphasize with science the relativity of knowledge. Yet here once more one may have to admit a certain weakness in sociological theorizing. Though the science would preferably base itself on verifiable knowledge, yet in practice, owing to the temporary lack of such knowledge in the newer psychology, it of necessity lapses into the sin of philosophizing on other than scientific data and methods. In discussions involving the use of the terms "worth" or "value," the "social will," or "social ideal," or "social purpose," or the "unity of knowledge," and the like, there is a metaphysical element almost inevitable under present conditions, especially if one is eager to work out at once a complete system of sociology. Yet perhaps some sins may be overlooked if one's sociological conscience is awake and the danger appreciated. In time such hypotheses may become verifiable, and until then one might better admit that there is some basis for charges of inconsistency.

Our final emphasis in the teaching of sociology consists in the attempt to develop in the student a sort of meliorism or optimism in respect to social problems; not a visionary optimism, in essence, fatalism, but an optimism founded on scientific knowledge, on the conviction that the progress of civilization lies in men's hands, and that by scientific prevision society can expedite its own development. Taking warning from the many failures of utopian dreamers, students are rather discouraged from becoming "reformers," but are urged to engage in the constructive movements of civilization. Honest daily work, high ideals, and a forward 
look represent a wiser attitude than any number of hobbies in respect to a reconstructed society patterned after a perfect model. This scientific optimism is stimulated by constant emphasis on the possibility of achievement. No normal child, it is argued, is so humbly born but that he by right training and environment may double his natural ability. Talent, genius, the capacity to achieve are dormant in the masses of our population and this potentiality should be made reality. Every student therefore is urged to develop his own personality so as to co-operate in the upbuilding processes of human society. Obviously this aspect may be so emphasized as to develop a sort of religious altruism and this may for a time be necessary. In that case sociology may temporarily form a sort of connecting link between the old and the new. While churches are hesitating on the brink of a sociological plunge it may be well for the sociologist to disport himself in the troubled waters and loudly to assert that the swimming is fine. When hesitation ends and the leap has been made, then the sociologist may climb on to the bank and criticize in cold blood the swimming exhibition before him.

In conclusion may $I$ in résumé briefly summarize the points we emphasize in the teaching of sociology? First and foremost a clear comprehension of the field of sociology including its relation to other sciences and its methods in handling data. Then a constant emphasis on those fundamental teachings that plainly have practical applications to social progress. And finally an inspirational uplift in the direction of courage and hopefulness, even though one has in the end to temper his impatience by the thought, that an ox-cart slowly reaching its destination on an ascending grade is surer of final success than a brakeless automobile speeding on an unknown road.

\section{DISCUSSION}

Edward C. Hayes, University of Illinois

The teaching of sociology presents a problem of matter and one of method.

The matter to be taught is broadly divided into two parts, first "General Sociology," or "Pure Sociology," or "Sociology Proper," and, second, that 
other body of instruction which is variously termed "Applied Sociology," "Social Economics," or "Social Technology."

The latter summarizes the results of experience and investigation with reference to activities which aim directly at social amelioration in relation to such matters as poverty, crime, immigration, race differences, and the specific dangers and opportunities characteristic of urban or rural communities.

The matter to be presented under "general" or "pure" sociology or sociology "proper" falls into at least five natural divisions.

First is general sociology in the narrowest sense, or what is sometimes referred to as "philosophical" sociology. This treats of such subjects as the scope and method of sociology, the definition of sociological concepts (social reality, a society, institution, custom, etc.) the correlation of these concepts with each other and with others defined by the special social sciences, the classification of all social realities, the kinds of causal conditions by which they are affected, the relation between society and the individual, the doctrines of sociological ethics, etc. The teachings of this division of sociology are partly preliminary to the teachings of the other divisions of pure sociology, and partly based upon them.

Second is psychologic sociology, which treats of the relations between activities (beliefs, desires, etc.) and the other activities, similar or dissimilar, by which they are environed; that is, the relations between the activities of an individual and the activities of his associates by which his own are evoked or modified, and so the building-up of the network of streaming activities possible only to individuals who are in association.

Third is comparative and genetic sociology, represented by such work as has been done by Letourneau, Lippert, Bastian, Westermarck, Sumner, and Thomas. This aims to lay a broad foundation of fact for our knowledge of the origin and succession of species of prevalent social activities and the evolution of the world of social reality.

The fourth division might be called statistical sociology, but that the word "statistical" refers to a method which may be employed in other divisions of sociology although it finds its most constant application here. This fourth division of sociology proper may be called biologic sociology. It deals with the problems of population, the effects upon social activities produced by racial and temperamental traits, and by physical contrasts between manufacturing and agricultural populations of similar stock, and by the physical consequences of prevalent vices, unsanitary housing, and the like.

The fifth division is geographic sociology, the most neglected of all, which studies the causal significance of natural physical environments in determining social activities.

With reference to the manner of teaching Sociology the only point which I will raise pertains to the order of presentation.

I think that most of us who are devoted to the teaching of sociology 
proper plunge the beginner into difficult abstract matter which is better adapted to the graduate student than to any but the brightest and most mature undergraduates. This has been my own practice and I propose to try a change of order and to arrange my course in "Sociology One" on "the principle of sixteen to one, sixteen parts fact and one part theory."

Most students who register for "Sociology One" expect a treatment of concrete social realities in which they have already at least a general interest; and they are surprised to be confronted by a body of undreamed-of abstractions. Besides, the natural development of intellectual interest for an individual or a people, seems to begin with definite realities which we wish to modify or control, and then by discovering that we must have deeper and broader comprehension, in order to secure control, to pass over to those generalities and abstractions which at first were repellent but which become absorbing.

I mean to begin by trying to describe the facts of American social life and the conditions by which they are determined. Our university is located in the country and so I intend to employ the stereopticon to show a large part of what is most instructive, not only in one but in many of our greatest cities, and in the country also, among the mountain whites, the lumber camps and mining camps, New England villages, southern plantations, train yards, harbors, factories, and the congested tenements of our immigrant host. And I think that the results of the numerous sociological investigations now going on should be carefully gathered up by a university and utilized for purposes of instruction. I refer to the investigations supported by the Sage endowment, and to such investigations as are being carried on in this city under the direction of Mr. Marsh, whose results supplied the materials for the congestion exhibit of a year ago, and of Mr. Allen, of the "Bureau of Municipal Research," and of Mr. Laidlaw, of the "Federation of Churches and Christian Organizations." Much of this material is presented in the form of tables and diagrams suitable for wall-charts or lantern slides, which can be reproduced, and in so far as it is accurate, should be valuable teaching material. Presently the students can be set to work upon exercises in computation and tabulation based upon data obtained from various sources.

All our presentation of descriptive material and concrete facts will be of value mainly in proportion as it is guided and interpreted by general concepts and leads up to comprehensive views. If in normal times there are in our country four million recipients of public charity, if most of the time during the past fifteen years from sixty to a hundred thousand tramps have been deployed over the United States, if these and numerous similar statements are true our aim must be not merely to state the facts but also to help the students toward a comprehension of the general situation which occasions the continuous recruiting of the standing army of the miserables.

This proposal to revise the character of the initial course in sociology 
is based on two considerations: First, that by sufficient heed to the most accessible realities-those of our own country and time-as well as to comparative and genetic sociology, we may be saved from getting too far from our facts, and becoming asphyxiated in abstractions, as men deeply interested in a new and complicated body of theory are in danger of doing; and, second, that we may lead the largest number of competent students, by the natural path, to an intelligent interest in the theoretical teachings of general sociology.

\section{James E. Hagerty, Ohio State University}

Before discussing the teaching of sociology we should be in agreement as to the question as to whom it is to be taught. Have we in mind the teaching of sociology to Sophomores, Juniors, Seniors or to graduate students? The class of people we teach will necessarily determine our methods.

As a rule the general course in economics in the American university is taught second-year students. I am going to assume that a course in sociology corresponding to this general course in economics may also be taught to second-year students. If so the subject-matter should be concrete, definite, and systematically arranged.

We are going through the same stage in the teaching of sociology formerly passed through in the teaching of economics and we can learn a great deal from the present methods of teaching economics. Formerly the textbooks in political economy devoted the first fifty or sixty pages to definition, the relation of political economy to other bodies of knowledge, its province, its purposes, the methods of investigation, etc. Recent writers have wisely omitted this class of subject-matter entirely. They have doubtless discovered that it is bad pedagogy to present the abstract and analytical phases of a science to students who know nothing of its subjectmatter. In many places we are making the same error in the teaching of sociology.

At the Ohio State University we have placed our elementary course in sociology on precisely the same plan as our elementary course in economics. We have a three-hour course per week extending through the year, which is a prerequisite to all other courses in sociology. This course is open to second-year students. At the outset we give four or five lectures on the evolution of society, emphasizing social phenomena. Our next division is devoted to the economic or physical basis of society. We next discuss the biological factors, including a study of races. The following divisions are then presented in order: the psychological factors, social structure, social control, social institutions, social pathology, and social progress. The Spring Term, or about one-fourth of the year, is devoted to practical problems in which the students are required to make an application of theories.

This, in brief, outlines the method we are pursuing, which is proving 
successful. We treat all subjects in this elementary course which are developed in our advanced or more technical courses. The student approaches the latter subjects with a broader point of view than he otherwise would have. The subject-matter presented in the elementary course is concrete and definite. No attempt whatever is made to present the various viewpoints of sociologists or the numerous questions on which they take issue. The natural way for a student to begin the study of any science is with the concrete, positive phenomena which constitutes its subject-matter.

\section{Thomas J. Riley, Washington University}

I recently visited a county teachers' meeting in Missouri. It was in the spring near the close of the school year. The discussion going on was concerning the teaching of geography. One of the teachers in telling about the progress of her class said, "We have just now got to Missouri," referring doubtless to the special study of her own state near the close of the textbook. Professor John Dewey, in his little book, The School and Society, states that a class in geography in the public schools at Moline, I11., knew much about the Mississippi River in the textbook, but had not connected the river of the book with the river on which the city is located. These are illustrations of what is likely to happen when the beginning of a study has to do with its definitions, problems, and relations. Students are likely not to make the connection of the things being studied with the facts of living that lie at their own doors.

It has been my experience in four years of trial that the best introduction to a course in elementary sociology is to study the social facts that may be observed in the community where the university is located. In beginning my work at the opening of the last year I instructed my class at its first meeting that they should visit some building in the process of construction, noting especially the division of labor and the necessary interdependence and co-ordination. At the second meeting of the class I found the students all qualified to illustrate and to discuss the topics I had assigned. When this had been considered $\mathrm{I}$ in like manner required them to report on physiographic control of social facts in their own city. By this method it seems to me I secured a lively interest on the part of the students, introduced them to an observational method and connected our study with the things lying about them.

The chairman assuring me that I have some time yet at my disposal I venture to ask those who advocate a psychological view of society to what extent they consider psychic forces competent to explain social phenomena; for example: When a plane of living that a family maintains becomes the plane of many families a standard of living for that group has been tacitly arrived at. Studies in the standard of living seem to have 
shown that this standard is determined partly by the necessities for food, clothing, and shelter and partly by the ideals, that is the traditions, beliefs, education, and ambitions of the families. These latter things are chiefly the psychic factors, but when the income is small these ideals are not able to find much expression in the standard of living that the class maintains. My question is not whether the psychic factors are more important than the economical factors in determining the standard of living, but whether the standard of living can be accounted for only in terms of psychic forces. It seems to me that such a thing as a standard of living for a class is determined chiefly by the economical and psychic factors together with perhaps several others as physical environment, etc.

\section{Dr. Rudolph M. Binder, New York University}

There are two classes of students in sociology-those who intend to devote two or three years to this subject, and may wish to specialize in it; and those who can give it but little time in one year. The former need and should receive as strict a scientific training as sociology is able to give. The latter-and their number is legion-need inspiration, contact with living problems and reform movements. In their case strict scientific methods are not applicable, and a general acquaintance with sociological principles is all that can be required. This class of students should nevertheless be encouraged, both because they will make better workers in their own fields through this elementary knowledge of sociology, and because some at least will find this study sufficiently profitable to pursue it farther.

\section{Professor Carl Kelsey, The University of Pennsylvania}

I am tremendously interested in the general trend of thought evidenced by the papers read this morning. It seems to me that we have spent altogether too much time in trying to justify our own existence and in marking out division lines between the older subjects and our own. The field of human knowledge is, after all, one and the different sciences represent but different viewpoints from which the field is studied. I believe that the future of sociological teaching is bright if we can restrict ourselves to the study of concrete problems, problems not in the sense of pathology alone but with clear recognition that all social phenomena, whether of advance or decay, involve problems. It is our business to study these and I can only hope that in our presentation to the classes we may in some measure adopt the magnificent and tremendous logic which characterizes the work of our honored Nestor, Professor Ward. 


\section{Professor Jerome Dowd of the University of Oklahoma}

Resolved, That the chair appoint a committee of ten, including the president of the Sociological Society, to make a report to the next meeting of the society, consisting of: First, a statement of the subject-matter of first courses now given in the colleges of the country; and, second, a suggestion of the subject-matter for a fundamental course to serve as a guide to sociological teachers and as a basis for advanced work.

\section{In support of the motion Professor Dowd said:}

There are two reasons for this motion: First, in taking rank as a science and in attaining to that dignity and respect which the importance of the subject and the wide interest in it demand, it seems to me desirable that sociology should standardize its fundamental courses in the same way that the fundamental courses of other sciences are standardized. For illustration, when a student takes Chemistry I, Physics I, Biology I, Economics I, or Law I, such course stands for a definite subject-matter, and enables the student to find an easy adjustment in going from one institution to another, and it forms a solid basis for advanced work.

Second, I believe that the concrete statement of the subject-matter of a fundamental course would harmonize and crystallize our views as to the scope and field of sociology to an extent that no amount of theoretical discussion could possibly do.

The resolution was adopted, and the following committee was appointed.1 Igro.

${ }^{1}$ For names of committee, see American Journal of Sociology, January, 